\title{
Comparison of Nutrition Screening and Assessment Parame- ters in Predicting Length of Hospital Stay
}

\author{
Susetyowati ${ }^{1 *}$, Hamam Hadi ${ }^{2}$, Mohammad Hakimi ${ }^{3}$ and Ahmad Husain Asdie ${ }^{3}$ \\ ${ }^{1}$ Department of Nutrition and Health, Universitas Gadjah Mada, Indonesia \\ ${ }^{2}$ Alma Ata University, Indonesia \\ ${ }^{3}$ Department of Internal Medicine, Universitas Gadjah Mada, Indonesia
}

*Corresponding author: Susetyowati, Department of Nutrition and Health, Universitas Gadjah Mada, Jalan Farmako, Sekip Utara, Yogyakarta, 55281, Indonesia, Tel: +6281-827-7781

\begin{abstract}
Background and objective: To compare the accuracy of five nutritional screening tools and to assess the most effective parameters in predicting Length of Hospital Stay (LOS).

Method: Prospective cohort study in Dr. Sardjito General Hospital, the central hospital in Yogyakarta Province, Indonesia. Subjects are 326 adult patients within 48 hours of hospital admission. We using The Simple Nutrition Screening Tool (SNST), Nutritional Risk Screening-2002 (NRS2002), Malnutrition Screening Tool (MST), Malnutrition Universal Screening Tool (MUST) and Short Nutritional Assessment Questioner (SNAQ), and Nutritional Assessment (anthropometric and biochemical measurements).

Results: The SNST, NRS-2002, MST, MUST, and SNAQ identified nutritional risk in $51 \% ; 55 \% ; 34 \% ; 60 \%$ and $38 \%$ of the patients, respectively. The SNST obtained the highest level of discrimination (0.87) compared to NRS-2002 (0.73), MST (0.77), MUST (0.76), and SNAQ (0.78). Patients at risk of malnutrition compared to those who are not, had a lower average value of Body Mass Index (BMI), Mid Upper Arm Circumference (MUAC), albumin, Haemoglobin $(\mathrm{Hb})$ and significantly higher Length of Stay (LOS) based on five Nutritional Screening Tools, except for the SNAQ. Malnutrition was associated with longer LOS with the highest value of Relative Risk (RR) were the SNST for Nutritional Screening Tools (1.76) and albumin for nutritional assessment parameters (1.37).
\end{abstract}

Conclusion: All the nutritional screening and assessment parameters can predict Length of Hospital Stay in patients but, the most appropriate one is the SNST.

\section{Keywords}

Malnutrition, Nutritional screening, Nutrition assessment, Length of hospital stay

\section{Introduction}

Malnutrition is one of the problems facing hospitalized patients [1]. Malnutrition may arise from prior hospitalization due to illness or inadequate nutrient intake [2]. The prevalence of malnutrition among hospitalized patients worldwide is quite high and reportedly ranges between 20-60\% [3-11]. A study among 298 patients in internal medicine and neurological diseases wards in Dr. Sardjito General Hospital Indonesia reported as many as $72.3 \%$ patients had hypo-albumineamia, $68.2 \%$ had aneamia, $43.3 \%$ had malnutrition based on the Body Mass Index (BMI) and $33.5 \%$ had malnutrition based on Subjective Global Assessment (SGA) (categories B and C) when admitted to hospital [12].

Malnutrition has been associated with higher rates of complications [1,5], higher mortality [13], higher cost of care $[1,14,15]$, longer Length of Hospital Stay (LOS) $[1,15,16]$ and readmission to the hospital [15]. Consensus about hospital malnutrition by the American Society for Parenteral and Enteral Nutrition (ASPEN) and the European Society of Enteral Nutrition (ESPEN) have agreed that malnutrition can worsen the clinical outcome of patients [17]. Regardless of the complications of malnutrition, there has been a fundamental lack of consensus on diagnostic criteria of malnutrition in clinical settings. Hence, the Global Leadership Initiative on Malnutrition (GLIM) was convened on standardizing the clinical practice of malnutrition diagnosis and reaching

Citation: Susetyowati, Hadi H, Hakimi M, Asdie AH (2018) Comparison of Nutrition Screening and Assessment Parameters in Predicting Length of Hospital Stay. J Nutri Med Diet Care 4:030. doi. org/10.23937/2572-3278.1510030

Accepted: December 03, 2018: Published: December 05, 2018

Copyright: (c) 2018 Susetyowati, et al. This is an open-access article distributed under the terms of the Creative Commons Attribution License, which permits unrestricted use, distribution, and reproduction in any medium, provided the original author and source are credited. 
global consensus on identification of criteria for diagnosis of malnutrition in clinical settings [18].

The GLIM was selected 3 phenotypic criteria (nonvolitional weight loss, low Body Mass Index, and reduced muscle mass) and 2 etiologic criteria (reduced food intake or assimilation, and inflammation or disease burden). At least, 1 phenotypic criteria and 1 etiologic criteria should be present to diagnose malnutrition [18].

Malnutrition, notably, undernutrition, caused by disesase-associated inflammatory or other mechanism. It is associated with disease or injury, consist of a combination of reduced food intake or assimilation and varying degrees of acute or chronic inflammation. This condition, in the long term, leading to decreased body composition and diminished biological function [17]. Body cell depletion due to reductions in energy and protein intake while, body cell inflammation due to the progressions of the disease [17]. Both of them contribute to anorexia, decreased food intake, as well as elevated metabolism and increased protein catabolism. All the changes may cause body composition degradation so it can be factors of malnutrition in hospitalized patients. For those reasons, nutrition screening must be done as well, so that Nutritional Care Process (NCP) can be done properly [19].

Nutrition screening is a quick and simple process that can be carried out by healthcare professionals [19]. It is an essential step before implementing the NCP to identify patients that would benefit from nutrition therapy [20]. Patients who are at nutrition risk based on nutrition screening result must be followed up to NCP. The Joint Commission on Accreditation of Healthcare Organizations are required to screen their patients for nutrition risk within 24 hours of hospital admission [21]. The ASPEN established a recommendation that nutritional screening should be performed for admitted patients to identify those at risk of malnutrition [22].

Academy of Nutrition and Dietetics (AND) stated that nutrition screening tool must be easy to complete, cost-effective, quick and able to identify individuals at risk of malnutrition [12]. The accuracy of the nutritional screening tool will affect the accuracy of the nutritional intervention that can prevent malnutrition in the hospital and rapid the recovery process $[23,24]$. The conclusion of the ASPEN forum discussion on malnutrition recommended that all patients during hospital admission should be screened and the nutrition screening should be repeated periodically [25].

The ESPEN consensus recommends the Nutritional Risk Screening (NRS) 2002 as good nutrition screening method. It has already been analyzed by several RCT studies [26]. Other literature review found that the Malnutrition Screening Tool (MST) was the nutrition screening tool with the highest ranking on the specific criteria [26], while The British Association of
Parenteral and Enteral Nutrition (BAPEN) recommends the Malnutrition Universal Screening Tool (MUST) [27]. Meanwhile, the Short Nutritional Assessment Questionnaire (SNAQ) is a valid method for early detection of malnutrition [28].

Based on the American Dietetic Association's Evidence Analysis Library, the NRS-2002 is the best nutritional screening tool with a grade I level that shows the best nutrition screening tool. Other screening tool such as the MST and MUST are categorized as grade II while the SNAQ is categorized as grade 5 [29]. Systematic review of 32 screening tools identified those adult patients completing the MUST performed in the fair to good range. The SGA, NRS-2002 and MUST performed well in predicting outcomes (i.e., length of stay, mortality or complications) [30].

In Indonesia, there is no nutrition screening tool which is the most appropriate and acceptable because most existing nutrition screening tools require mathematical calculations and data that can only be revealed by skilled healthcare professional [12]. In addition, not all hospital in Indonesia have adequate anthropometric equipment and also rarely regularly weigh patients, so their weight history is unknown. For these reasons, Susetyowati [12] has developed a new nutritional screening tool named the Simple Nutrition Screening Tool (SNST) which has been proven valid to detect patients at risk of malnutrition compared with the gold standard, the SGA (sensitivity $91 \%$; specificity $80 \%$ ). The SNST also has good reliability among dietitians (kappa 0.803 ), dietitian and nurses (kappa 0.653), as well as a dietitians and food service officers (kappa 0.718) [12].

After nutrition screening is carried out, nutrition assessment must be performed to obtain severity of malnutrition and its causes. It involves several measurement to determine nutritional status. It classified into two categories, Subjective Global Assessment (SGA) and Objective Data Assessment (ODA). The ODA consist of various objective analyses, for instance Bioimpedance Analysis (BIA), DualEnergy X-ray Absorptiometry (DEXA), and Computed Tomography (CT) scan [31].

This study aimed to 1) Compare the accuracy of five nutritional screening tools in identifying patients with malnutrition as assessed by the SGA and other nutrition assessment tools and 2) To assess which nutrition screening (SNST, NRS-2002, MST, MUST or SNAQ) and nutrition assessment parameters were the most effective for predicting LOS.

\section{Materials and Methods}

This study was a prospective cohort study conducted in Dr. Sardjito General Hospital, the central hospital in Yogyakarta Province, Indonesia. The study received ethical clearance from the Ethics Committee of the Faculty of Medicine, Universitas Gadjah Mada, 
Indonesia. Written informed consent was obtained from all participants, adult patients who were admitted to the internal and nerve wards without pregnancy or postpartum conditions.

Within 48 hours of hospital admission, SNST, NRS2002, MST, MUST, SNAQ and SGA were administered by trained staff to all patients. The SNST, as the newest nutrition screening tool developed in Indonesia, is a simple nutritional screening tool with 6 questions that do not include anthropometric and weight loss measurements. It can be conducted in a short period of time ranging from 3 to 5 minutes for each patient [12]. The SNST questions were 1) Does the patient look thin? 2) Do your clothes feel looser? 3) Have you recently lost weight unintentionally ( 6 months)? 4) Have you decreased food intake during the past weeks? 5) Do you feel weak, sluggish, and not powerful? and 6) Do you suffer from a disease that results in a change in the amount or type of food you eat? Patients who were at risk of malnutrition at admission were identified using each nutrition tool's cut off points, NRS-2002 $\geq 3$; MST $\geq 2$; SNST $\geq 3$; MUST $\geq 2$ and SNAQ $\geq 2$, and were categorized into two groups: Not at risk and at risk [28]. The SGA, a nutritional assessment tool that consists of the patient's history and physical examination, was categorized as well nourished (SGA A) or malnourished or at risk of malnutrition (SGA B or SGA C) [31].

Anthropometric and biochemical measurements were performed for every patient who was admitted to Dr. Sardjito General Hospital. Anthropometric measurements were obtained using standardized procedures, and all tools had been calibrated. Body weight was measured with electronic digital scales and height was measured by microtoise to the nearest 0.5 $\mathrm{kg}$ and $0.5 \mathrm{~cm}$, respectively. Patients who are unable to stand were measured by height estimation with knee length and arm span measurements. The Mid Upper Arm Circumference (MUAC) was measured by measuring tape at the middle of arm's length. Biochemical data were obtained from blood sample analyses in the laboratory of Faculty of Medicine, Universitas Gadjah Mada, Indonesia. Instan Nutritional Assessment (INA) was obtained from albumin and Total Lymphocyte Count (TLC). It was classified into four degrees of malnutrition: $1^{\text {st }}$ degree (albumin $\geq 3.5 \mathrm{~g} / \mathrm{l}$ and TLC $\geq 1500 \mathrm{mg} / \mathrm{l}$ ); $2^{\text {nd }}$ degree (albumin $\geq 3.5 \mathrm{~g} / \mathrm{l}$ and $\mathrm{TLC}<1500 \mathrm{mg} / \mathrm{l}$ ); $3^{\text {rd }}$ degree (albumin $<3.5 \mathrm{~g} / \mathrm{l}$ and TLC $\geq$ $1500 \mathrm{mg} / \mathrm{l}$ ); $4^{\text {th }}$ degree (albumin $<3.5 \mathrm{~g} / \mathrm{l}$ and $\mathrm{TLC}<1500$ $\mathrm{mg} / \mathrm{I})[30]$. We divided the INA into two categorized to resume the prevalence of malnutrition: Class I $\left(1^{\text {st }}\right.$ degree) is not malnutrition and Class II $\left(2^{\text {nd }}, 3^{\text {rd }}\right.$, and $4^{\text {th }}$ degree) is malnutrition.

Patient's characteristics were presented using descriptive analyses. The sensitivity, specificity, Positive Predictive Value (PPV), and Negative Predictive Value (NPV) were calculated to compare the accuracy of each screening tool in detecting malnutrition. The Area Under Curve (AUC) was calculated as part of validity testing to determine the discrimination value of the Nutrition Screening Tool. Discrimination values of AUC determine the accuracy of nutrition screening tool to detect malnutrition [32]. Values for each nutrition screening tool were interpreted as acceptable $(0.70$ $0.80)$, excellent $(0.80-0.90)$, or outstanding or the highest level (>0.90) [32]. An independent t-test was performed to compare the nutrition screening tools with the anthropometric and biochemical measurements and the LOS. Categorical differences between groups not at risk and at risk of malnutrition with the LOS were analyzed using Chi-squared testing. Significance was determined by the $\mathrm{P}$ value $<0.05$ with $95 \% \mathrm{Cl}$.

\section{Results}

In this study, we included 326 patients (135 males and 191 females), predominantly < 65 years of age $(77.6 \%)$, who were hospitalized in the internal medicine ward as much as $84 \%$, and $16 \%$ in the nerve ward (Table 1 ).

The nutrition screening tools identified patients with nutritional risk differently. Figure 1 , showed that nutritional screening by the SNST, NRS-2002 and MUST identified patient at risk of malnutrition as $51 \%, 55 \%$ and $60 \%$ respectively, whereas the MST and SNAQ identified patients at risk of malnutrition were only $34 \%$ and $38 \%$, respectively.

The accuracy of each nutrition screening tool in identifying malnutrition as determined by SGA is shown in Table 2. The SNST had the highest sensitivity and NPV. The MST and SNAQ had a high specificity but low sensitivity, which means they can miss identifying many malnutrition patients. The SNST was shown to be an excellent nutrition screening tool because it had the highest AUC discrimination.

The association between the nutrition screening tool's subscale of the SNST, NRS-2002, MST, MUST and SNAQ with nutritional assessment such as the MUAC, $\mathrm{BMI}$, albumin, and Hemoglobin $(\mathrm{Hb})$ is shown in Table 3. There are significant associations between all Nutrition Screening Tools with all nutritional status parameters $(p<0.005)$, except for the SNAQ with $\mathrm{Hb}$. The analysis showed that patients at risk of malnutrition had a lower average value for the objective parameters i.e., The

Table 1: Participants Characteristics $(n=326)$.

\begin{tabular}{|l|l|}
\hline Evaluated data & Obtained value \\
\hline Sex & $135(41.4 \%)$ \\
\hline Males & $191(58.6 \%)$ \\
\hline Females & \\
\hline Age & $253(77.6 \%)$ \\
\hline$<65$ Years & $73(22.4 \%)$ \\
\hline$\geq 65$ Years & \\
\hline Disease & $145(44.5 \%)$ \\
\hline Cancer & $181(55.5 \%)$ \\
\hline Non-cancer & \\
\hline
\end{tabular}




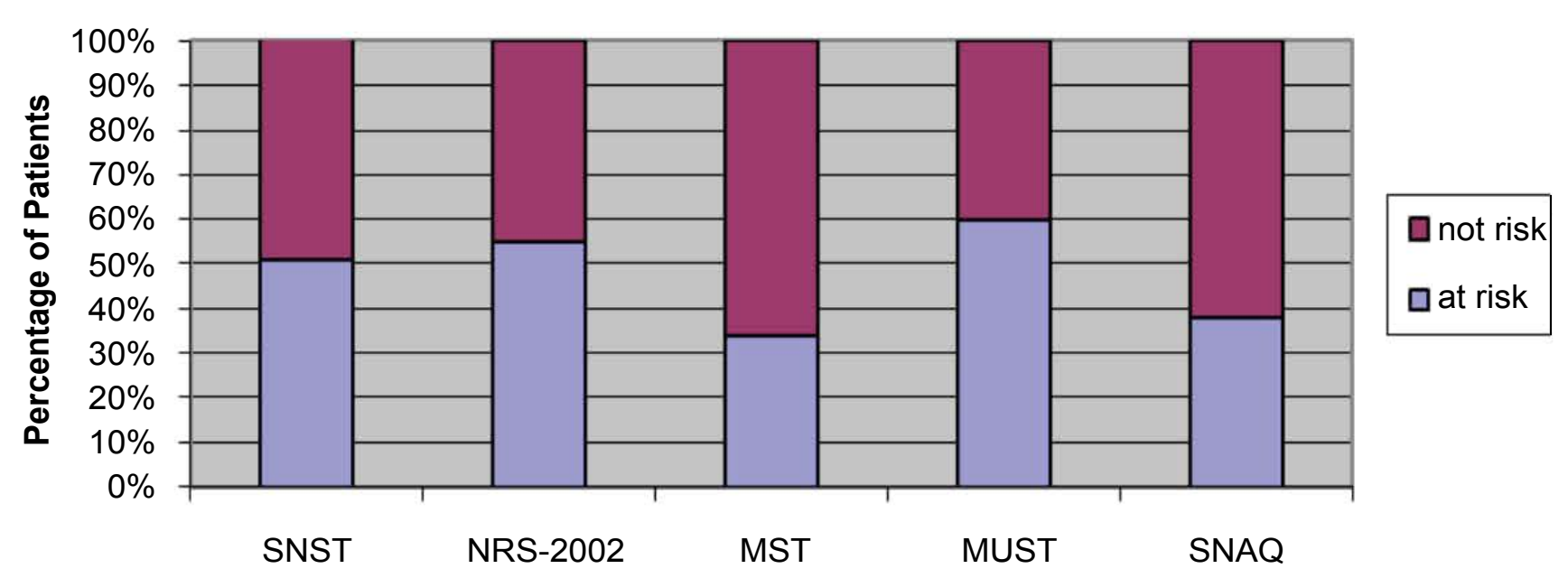

\section{Nutrition Screening Tools}

Figure 1: Prevalence of risk of malnutrition based on different nutritional screening tool.

Table 2: Accuracy of screening tools at identify malnutrition (as determined by Subjective Global Assessnent).

\begin{tabular}{|c|c|c|c|c|c|c|}
\hline $\begin{array}{l}\text { Screening } \\
\text { tool }\end{array}$ & Sensitivity $(95 \% \mathrm{CI})$ & Specificity $(95 \% \mathrm{CI})$ & $(95 \% \mathrm{Cl})$ & NPV $\quad(95 \% \mathrm{Cl})$ & AUC $(95 \% \mathrm{Cl})$ & $\begin{array}{l}\text { AUC } \\
\text { discrimination }\end{array}$ \\
\hline SNST & $91.2 \%(85.3-95.2)$ & $81.6 \%(75.1-87)$ & $80.2 \%(73.4-86)$ & $91.8 \%(86.4-95.6)$ & $\begin{array}{l}0.87 \\
(0.82-0.91) \\
\end{array}$ & Excellent \\
\hline NRS-2002 & $79.6 \%(72.2-85.8)$ & $65.9 \%(58.5-72.8)$ & $65.7 \%(58.3-72.7)$ & $79.7 \%(72.3-85.9)$ & \begin{tabular}{|l|}
0.73 \\
$(0.67-0.79)$ \\
\end{tabular} & Acceptable \\
\hline MST & $62.6 \%(54.2-70.4)$ & $89.4 \%(83.9-93.5)$ & $82.9 \%(74.6-89.4)$ & $74.4 \%(68-80.1)$ & \begin{tabular}{|l|}
0.77 \\
$(0.71-0.83)$ \\
\end{tabular} & Acceptable \\
\hline MUST & $88.3 \%(81.7-93.2)$ & \begin{tabular}{|l|}
$64 \%$ \\
$(56.5-71.1)$ \\
\end{tabular} & $65.4 \%(58.1-72.2)$ & $87.7 \%(80.8-92.8)$ & \begin{tabular}{|l|}
0.76 \\
$(0.71-0.81)$
\end{tabular} & Acceptable \\
\hline SNAQ & \begin{tabular}{|l}
$68 \%$ \\
$(59.8-75.5)$ \\
\end{tabular} & $\begin{array}{l}86 \% \\
(80.1-90.7)\end{array}$ & $\begin{array}{l}80 \% \\
(71.9-86.6)\end{array}$ & $76.6 \%(70.1-82.3)$ & $\begin{array}{l}0.78 \\
(0.72-0.83)\end{array}$ & Acceptable \\
\hline
\end{tabular}

SNST: Simple Nutrition Screening Tool; NRS: Nutritional Risk Screening-2002; MST: Malnutrition Screening Tool; MUST: Malnutrition Universal Screening Tool; and SNAQ: Short Nutritional Assessment Questioner; PPV: Positive Predictive Value; NPV: Negative Predictive Value; CI: Confident Interval; AUC: Area Under the Curve.

${ }^{*}$ Classification of AUC (range 0-1); acceptable 0.70-0.80, excellent 0.80-0.90.

Table 3: Association between nutrition screening parameter by SNST, NRS-2002, MST, MUST, SNAQ with anthropometric and biochemical measurement.

\begin{tabular}{|c|c|c|c|c|c|c|c|c|c|c|}
\hline \multirow[t]{2}{*}{ Outcomes } & \multicolumn{2}{|l|}{ SNST } & \multicolumn{2}{|c|}{ NRS-2002 } & \multicolumn{2}{|l|}{ MST } & \multicolumn{2}{|c|}{ MUST } & \multicolumn{2}{|c|}{ SNAQ } \\
\hline & $1^{\dagger}$ & $0^{\ddagger}$ & $1^{\dagger}$ & $0^{\ddagger}$ & $1^{\dagger}$ & $0^{\ddagger}$ & $1^{\dagger}$ & $0^{\ddagger}$ & $1^{\dagger}$ & $0^{\ddagger}$ \\
\hline BMI $\left(\mathrm{kg} / \mathrm{m}^{2}\right)$ & 18.9 & 22.5 & 18.5 & 23.5 & 19.1 & 21.5 & 18.5 & 24 & 19.3 & 21.7 \\
\hline $\operatorname{Sig}(P)^{*}$ & 0.001 & & 0.001 & & 0.001 & & 0.001 & & 0.001 & \\
\hline $\operatorname{MUAC}(\mathrm{cm})$ & 23 & 27 & 23.1 & 27.1 & 23.5 & 25.8 & 23 & 27.9 & 23.6 & 25.8 \\
\hline $\operatorname{Sig}(P)^{*}$ & 0.001 & & 0.001 & & 0.001 & & 0.001 & & 0.001 & \\
\hline Albumin $(\mathrm{g} / \mathrm{dl})$ & 2.84 & 3.33 & 2.95 & 3.23 & 2.88 & 3.17 & 2.98 & 3.28 & 2.91 & 3.18 \\
\hline $\operatorname{Sig}(P)^{*}$ & 0.001 & & 0.001 & & 0.001 & & 0.001 & & 0.003 & \\
\hline $\mathrm{Hb}(\mathrm{g} / \mathrm{dl})$ & 10.7 & 11.9 & 10.8 & 11.9 & 10.8 & 11.6 & 10.9 & 12 & 10.9 & 11.5 \\
\hline $\operatorname{Sig}(P)^{*}$ & 0.001 & & 0.001 & & 0.006 & & 0.001 & & 0.062 & \\
\hline
\end{tabular}

†: Risk of malnutrition (medium and high); ‡: Not and low risk of malnutrition; "Sig (p): Risk malnutrition versus not risk malnutrition patients with the same screening; BMI: Body Mass Index; MUAC: Mid Upper Arm Circumference; Hb: Hemoglobin.

BMI, MUAC, albumin and $\mathrm{Hb}$ compared with patients who are not at risk of malnutrition.

Table 4, serves analysis of risk of malnutrition and nutritional status based on patient's disease in each nutrition screening tool and the SGA. Patients who are diagnosed cancer had higher risk of malnutrition based on the SNST, NRS-2002, and MUST, significantly.
The comparison of the LOS in each Nutritional Screening Tool and nutritional assessment parameters is presented in Table 5. Patients at risk of malnutrition based on Nutritional Screening Tools and patients at malnutrition based on nutritional assessment parameters had longer lengths of stay compared to patient's not at risk of malnutrition $(p<0.05)$. 
Table 4: Association between SGA and Nutrition Screening Tools with disease of patient $(n=326)$.

\begin{tabular}{|c|c|c|c|c|c|}
\hline \multirow{3}{*}{ Variable } & \multicolumn{2}{|l|}{ Disease } & \multirow{3}{*}{ n (\%) } & \multirow{3}{*}{\begin{tabular}{|l} 
RR \\
(CI 95\%) \\
\end{tabular}} & \multirow{3}{*}{ Sig (p) } \\
\hline & Cancer & Non-Cancer & & & \\
\hline & n (\%) & n (\%) & & & \\
\hline SGA & $66(45)$ & $81(55)$ & $147(100)$ & 1.024 & \multirow{3}{*}{0.468} \\
\hline Malnutrition & $79(44)$ & $100(56)$ & $179(100)$ & $(0.803-1.306)$ & \\
\hline \multicolumn{5}{|c|}{ Well-nourished } & \\
\hline SNST & $90(54)$ & $77(46)$ & $167(100)$ & 1.591 & \multirow{3}{*}{$<0.001$} \\
\hline At risk & $55(34)$ & $104(66)$ & $159(100)$ & $(1.226-2.064)$ & \\
\hline \multicolumn{5}{|l|}{ Not risk } & \\
\hline NRS-2002 & $94(53)$ & $84(47)$ & $178(100)$ & 1.541 & \multirow{3}{*}{$0.001^{*}$} \\
\hline At risk & $51(34)$ & $97(66)$ & $148(100)$ & $(1.186-2.002)$ & \\
\hline \multicolumn{5}{|l|}{ Not risk } & \\
\hline MST & $50(45)$ & $61(55)$ & $111(100)$ & 1.029 & \multirow{3}{*}{0.46} \\
\hline At risk & $95(44)$ & $120(56)$ & $215(100)$ & $(0.798-1.326)$ & \\
\hline \multicolumn{5}{|l|}{ Not risk } & \\
\hline MUST & $98(51)$ & 93 (49) & $191(100)$ & 1.454 & \multirow{3}{*}{$0.003^{*}$} \\
\hline At risk & $47(35)$ & $88(65)$ & $135(100)$ & $(1.114-1.898)$ & \\
\hline \multicolumn{5}{|l|}{ Not risk } & \\
\hline SNAQ & $57(46)$ & $68(54)$ & $125(100)$ & 1.066 & \multirow{3}{*}{0.342} \\
\hline At risk & $88(43)$ & $113(57)$ & $201(100)$ & $(0.837-1.359)$ & \\
\hline Not risk & & & & & \\
\hline
\end{tabular}

SGA: Subjective Global Assessment; SNST: Simple Nutrition Screening Tool; NRS: Nutritional Risk Screening; MST: Malnutrition Screening Tool; MUST: Malnutrition Universal Screening Tool; SNAQ: Short Nutritional Assessment Question.

*Sig (p): Risk malnutrition versus not risk malnutrition patients with the same screening.

Table 5: Association between age, disease, BMI, albumin, MUAC and mutritional Screening by the SNST, NRS-2002, MST, MUST and SNAQ with Length of hospital stay (LOS).

\begin{tabular}{|c|c|c|c|c|c|c|c|}
\hline \multirow{3}{*}{ Variable } & \multicolumn{4}{|c|}{ LOS } & \multirow{3}{*}{ n (\%) } & \multirow{3}{*}{$\begin{array}{l}\text { RR } \\
(95 \% \mathrm{CI})\end{array}$} & \multirow{3}{*}{ Sig (p) } \\
\hline & \multicolumn{2}{|c|}{$\geq 7$ days } & \multicolumn{2}{|c|}{ 1-6 days } & & & \\
\hline & n & $\%$ & $\mathbf{N}$ & $\%$ & & & \\
\hline \multicolumn{8}{|c|}{ Nutrition Screening Tools } \\
\hline \multicolumn{8}{|c|}{ SNST } \\
\hline At Risk & 97 & 58 & 70 & 42 & $167(100)$ & 1.71 & \multirow{2}{*}{$<0.001^{*}$} \\
\hline Not risk & 54 & 34 & 105 & 66 & $159(100)$ & $(1.32-1.98)$ & \\
\hline \multicolumn{8}{|l|}{ NRS-2002 } \\
\hline At Risk & 94 & 53 & 84 & 47 & $178(100)$ & 1.37 & \multirow{2}{*}{$0.007^{*}$} \\
\hline Not risk & 57 & 38 & 91 & 62 & $148(100)$ & $(1.21-1.87)$ & \\
\hline \multicolumn{8}{|l|}{ MST } \\
\hline At Risk & 67 & 60 & 44 & 40 & $111(100)$ & 1.54 & \multirow{2}{*}{$<0.001^{*}$} \\
\hline Not risk & 84 & 39 & 131 & 61 & $215(100)$ & $(1.20-1.89)$ & \\
\hline \multicolumn{8}{|l|}{ MUST } \\
\hline At Risk & 102 & 53 & 89 & 47 & $191(100)$ & 1.47 & \multirow{2}{*}{$0.001^{*}$} \\
\hline Not risk & 49 & 36 & 86 & 64 & $135(100)$ & $(1.11-1.38)$ & \\
\hline \multicolumn{8}{|l|}{ SNAQ } \\
\hline At Risk & 69 & 55 & 56 & 45 & $125(100)$ & 1.35 & \multirow{2}{*}{$0.011^{*}$} \\
\hline Not risk & 82 & 41 & 119 & 59 & $201(100)$ & $(1.01-1.72)$ & \\
\hline \multicolumn{8}{|c|}{ Nutrition Assessment Tools } \\
\hline \multicolumn{8}{|c|}{ BMI $\left(\mathbf{k g} / \mathbf{m}^{2)}\right)$} \\
\hline$<18.5$ & 52 & 53 & 47 & 47 & $99(100)$ & 1.50 & \multirow{2}{*}{$0.004^{*}$} \\
\hline$\geq 18.5$ & 59 & 35 & 110 & 65 & $169(100)$ & $(1.04-2.78)$ & \\
\hline \multicolumn{8}{|l|}{ Albumin (g/l) } \\
\hline$<3.5$ & 108 & 59 & 75 & 41 & $183(100)$ & 2.12 & \multirow{2}{*}{$<0.001^{*}$} \\
\hline$\geq 3.5$ & 22 & 28 & 57 & 72 & $79(100)$ & $(1.12-2.66)$ & \\
\hline \multicolumn{8}{|l|}{ TLC (mg/l) } \\
\hline$<1500$ & 79 & 53 & 71 & 47 & $150(100)$ & 1.23 & \multirow{2}{*}{0.06} \\
\hline$\geq 1500$ & 60 & 43 & 80 & 57 & $140(100)$ & $(0.69-2.23)$ & \\
\hline \multicolumn{8}{|l|}{ MUAC (cm) } \\
\hline$<23.5$ & 65 & 47 & 73 & 53 & $138(100)$ & 1.10 & \multirow{2}{*}{0.272} \\
\hline$\geq 23.5$ & 70 & 43 & 93 & 57 & $163(100)$ & $(0.57-1.18)$ & \\
\hline
\end{tabular}




\begin{tabular}{|c|c|c|c|c|c|c|c|}
\hline \multicolumn{8}{|l|}{ INA } \\
\hline Class II & 107 & 59 & 73 & 41 & $180(100)$ & 2.11 & \multirow{2}{*}{$<0.001^{*}$} \\
\hline Class I & 22 & 28 & 56 & 72 & $78(100)$ & $(1.03-2.56)$ & \\
\hline \multicolumn{8}{|l|}{ Others } \\
\hline \multicolumn{8}{|l|}{ Age } \\
\hline$\geq 65$ Years & 38 & 52 & 35 & 62 & 73 (100) & 1.17 & \multirow{2}{*}{0.163} \\
\hline$<65$ Years & 113 & 45 & 140 & 55 & $253(100)$ & $(0.79-1.72)$ & \\
\hline \multicolumn{8}{|l|}{ Disease } \\
\hline Cancer & 68 & 47 & 77 & 53 & $145(100)$ & 1.13 & \multirow{2}{*}{0.444} \\
\hline Non-cancer & 75 & 46 & 90 & 54 & $181(100)$ & $(0.16-1.21)$ & \\
\hline
\end{tabular}

BMI: Body Mass Index; TLC: Total Lymphocyte Count; MUAC: Mid Upper Arm Circumference; INA: Instant Nutritional Assessment; SNST: Simple Nutrition Screening Tool; NRS: Nutritional Risk Screening; MST: Malnutrition Screening Tool; MUST: Malnutrition Universal Screening Tool; SNAQ: Short Nutritional Assessment Question.

Nutritional Screening Tools based on The SNST and the MST, and nutritional assessment parameters based on albumin and INA were the best tools to predict the LOS of patients $(p<0.001)$.

\section{Discussion}

There are some screening tools that have been recommended for identifying patients at risk of malnutrition, such as the NRS-2002, MUST, SNAQ, and MUST $[9,19]$. The NRS-2002 is a good nutrition screening tool with grade I, while the MST is a fair Nutritional Screening Tool with grade II [19]. Regular nutritional screening for hospitalized patients is recommended by national, European and American guidelines [21,32].

This study showed, the prevalence of cases at risk for malnutrition among hospitalized patients at the time of admission has ranged from $34-60 \%$. This is slightly higher compared to other studies (20-50\%) [4,25]. Nutrition screening is recommended as the first step in nutrition care to detect early identification and treatment of malnutrition [21,33]. To improve nutrition care, the feed-Medical Education (M.E.) Global Study Group recommends a Nutrition Care Pathway that consist of screening patient's, nutrition status on admission, interventing promptly when needed and followingup routinely with adjustment and reinforcement of nutrition care plans [34].

The performance of each screening tool in identifying malnutrition as determined by the SGA is presented in Table 2. Ideally, such a tool would identify all malnourished patients for assessment (high sensitivity), with a only positive screen result identifying well-nourished patients (High Positive Predictive Value) [29]. The SNST, NRS 2002, and MUST had a high sensitivity (91\%; 79\%; 88\%). The MST and SNAQ were highly specific but had a low sensitivity (62\% and 68\%), indicating that many malnourished patients could be missed using these tools, specially using the SNAQ.

Based on the BAPEN recommendation of nutrition screening tool, the MUST was the best indicator to distinguish between patients who are at risk or not at risk of malnutrition as determined by $\mathrm{BMI}$ ranging from $18.5 \mathrm{~kg} / \mathrm{m}^{2}$ to $24 \mathrm{~kg} / \mathrm{m}^{2}$ or by the MUAC ranging from
$23 \mathrm{~cm}$ to $27.9 \mathrm{~cm}$. These conditions occur because the first step in conducting the MUST is performing weightheight measurements to interpret the BMI. Although the SNST is a newly developed Nutritional Screening Tool, it had the same results in predicting objective nutrition parameters with other international screening tools. A previous study showed that the SNST had good agreement not only with SGA but also with all anthropometric and biochemical measurements and that it had lower values of BMI, MUAC, albumin levels, Hemoglobin and TLC in patients at risk of malnutrition compared to patient who are not at risk of malnutrition [12].

In this study, almost half of patients are diagnosed cancer and they tend to be at risk of malnutrition, significantly based on SNST, NRS-2002 and MUST. Malnutrition in cancer patients can develop at any time during the disease, even at diagnosis yet, it generally worsens as the disease progresses and treatments [34]. The main factor of malnutrition in cancer patients is cachexia that can be responsible for mortality in onethird of cancer patients. Cachexia is defined as a weight loss $>5 \%$ in the last 6 months. Thus, with chronic illness, even a low rate of weight loss can give increase to cachexia. Previous study found that cachexia-anorexia syndrome has been described in $20-40 \%$ of cancer patients [34]. Based on the result of the study, the SNST, NRS-2002 and MUST present significant result to predict malnutrition in cancer patients. Previous finding also stated that the NRS-2002 and MUST are recommended to be Nutrition Screening Tools in cancer patients [35].

The SNST has been analyzed by Mayasari, et al. [36] that stated subjects who were at risk for malnutrition according SNST had significantly lower values of BMI, MUAC, albumin, Hemoglobin and TLC. The SNST has good validity to identify risk of malnutrition on hospitalized elderly patients. Another previous study also found that SNST is better than NRS-2002 to predict malnutrition based on the subjective assessment (SGA and Dialysis Malnutrition Score or DMS) in hemodialysis patients [37].

Our study, which compared the SNST, NRS-2002, MST, MUST, and SNAQ also showed these tools significantly 
correlated with a longer length of stay, $>7$ days (RR $1.76 ; 1.43 ; 1.65 ; 1.29 ; 1.12)$. Another study also showed the same result, having found malnutrition assessed by the SNAQ, MUST, and NRS-2002 was associated with a longer hospital stay [38]. The systematic review by Schueren, et al. found that the SGA, NRS-2002 and MUST performed well in predicting outcomes (i.e., length of stay, mortality or complications) [28]. From this analysis, it is clear that the SNST, NRS 2002, and MST tools were better at predicting the LOS and discharge status. Additionally, the SNST itself is a powerful Nutrition Screening Tool because it is rapid and easy to administer.

Comparing the BMI, albumin, TLC, MUAC, and INA also showed there nutritional assessment parameters significantly correlated with a longer length of stay, > 7 days, except MUAC. Previous study also showed the same result that malnutrition assessed by $\mathrm{BMI}$, albumin, TLC, and INA was associated with a Longer of Hospital Stay $(p<0.001)$ [32]. From the present study result, it is clear that BMI, albumin, TLC, and INA were better at predicting the LOS compared to the MUAC as nutrition assessment tool.

Malnutrition or reduction in the nutritional status causing some negative impact in patients. A metaanalysis from 27 randomized controlled trials (RCT) in 1710 patients and $30 \mathrm{RCT}$ in 3250 patients has reported a significant correlation between malnutrition and disease complications, infection and mortality rate [39]. Result of other studies also show reduction in the nutritional status of hospitalized patients, regardless of the nutritional status' before entering the hospital, is correlated with high hospital costs and long treatment $[2,4,22,39,40]$. The analysis in the present study, which were significant, are that the average length of stay in patients at risk of malnutrition is longer than that of patients who are not at risk of malnutrition.

Diagnosis of malnutrition should be carry out after patient is diagnosed at risk of malnutrition. It is the main factor to conduct nutrition intervention in order to minimize the decline in nutrition outcome. The ASPEN, ESPEN, FELANPE and PENSA was constituted to form GLIM for reaching broader global consensus in defining and characterizing malnutrition $[17,18]$. There are two catagories for diagnosis of malnutrition: Phenotypic criteria and etiologic criteria. At least, 1 phenotypic criteria and 1 etiologic criteria should be present to diagnose malnutrition [18].

Three phenotypic criteria are: (1) Weight loss (\%), > $5 \%$ within past 6 months or $>10 \%$ beyond 6 months; (2) Low BMI $\left(\mathrm{kg} / \mathrm{m}^{2}\right),<20$ if $<70$ years or $<22$ if $>70$ years, and $<18.5$ if $<70$ years or $<20$ if $>70$ years for Asia; (3) Reduced muscle mass, by validated body composition measuring techniques. On the other hand, etiologic criteria has two categories: 1) Reduced food intake or assimilation, $\leq 50 \%$ of energy requirement for
$>1$ week, or any reduction for $>2$ weeks, or any chronic gastrointestinal condition that adversely impacts food assimilation or absorption; 2) Inflammation, acute disease/injury or chronic disease-related $[17,18]$.

Nutrition assessment tools is used to make diagnosis of malnutrition. The subjective (SGA) and objective (ODA) assessment can be performed to obtain information about nutrition status in clinical setting. Subjective assesses nutritional status based on the features of medical history and physical examination. This tool widely used in clinical setting. In addition, objective assessment provided information from anthropometry, bioimpedance analysis (BIA), dualenergy X-ray absorptiometry (DEXA), computed tomography (CT) scan, magnetic resonance imagine (MRI), laboratory and functional tests [31]. In the last couple years, the ODA have been developed and able to obtain precise and accurate results so that, it will cause better nutrition intervention in patients [31]. Most nutrition assessment tools have weakness. Therefore, combination of various parameters should be applied and all medical staff members need to understand the features of each method.

All Nutrition Screening Tools can be used in clinical setting because the AUC discrimination are excellent anc acceptable as determined by the SGA for gold standard. In addition, they are significantly associated with all objective assessment tools. However, the NRS-2002, MUST and SNST are Nutrition Screening Tools among analyzed should be especially used in daily practice. They have predominance over others. For instance, the MUST is screening tool that recommended by BAPEN. On the other hand, the NRS-2002 is recommended screening tool by ESPEN for clinical setting. It consists of complete variables such as nutrition intake, weight loss, appetite, and diseases. In addition, It has already been analyzed by several RCT studies [26]. In addition, the SNST should be considered to be one of valid and reliable screening tool because it is more simple and has been analyzed in clinical setting [12,36,37,41].

Some limitations of the study should also be acknowledged. There are vary of diseases such as infection and non-infection diseases, included cancer so, they are affected to the LOS. In addition, most of patients in cancer was being hospitalized to cytocyte therapy so, the LOS was being shorter automatically. On the other hand, we did not assess the nutritional status using objective assessment tools such as BIA and DEXA.

\section{Conclusion and Recommendation}

The SNST, NRS-2002, MST, MUST, and SNAQ and nutritional status based on anthropometric and biochemical measurements have significant correlations with LOS means that lower nutrition screening and nutritional status will have longer LOS. All the Nutritional Screening Tool are appropriate in predicting 
malnutrition on hospitalized patients in Indonesia. From this research, we recommend routine administration of the SNST to all patients upon hospital admission. Further research should explore the use of nutritional screening and intervention before, during and after hospitalization to ensure the appropriate nutritional intervention.

\section{Source of Support}

Faculty of Medicine, Public Health and Nursing, Universitas Gadjah Mada, Indonesia, as a research funding.

\section{Statement of Equal Author's Contribution}

We declare that each author:

1. Make substantial contributions to conception and design, and/or acquisition of data, and/or analysis and interpretation of data.

2. Draft the article or revising it critically for important intellectual content.

3. Give final approval of the version to be submitted and any revised version.

Each author have participated sufficiently in the work to take public responsibility for appropriate portion of the content, as we write below:

\begin{tabular}{|l|l|}
\hline Author & Contribution to article \\
\hline $\begin{array}{l}\text { Dr. Susetyowati, DCN, } \\
\text { M.Kes }\end{array}$ & $\begin{array}{l}\text { Performed analysis on all } \\
\text { samples, interpreted data, } \\
\text { wrote manuscript and acted } \\
\text { as corresponding author. }\end{array}$ \\
\hline Prof. Hamam Hadi, MD & $\begin{array}{l}\text { Helped in data } \\
\text { interpretation and } \\
\text { manuscript evaluation. }\end{array}$ \\
\hline $\begin{array}{l}\text { Prof. Mohammad } \\
\text { Hakimi, MD }\end{array}$ & $\begin{array}{l}\text { Helped to evaluate and edit } \\
\text { the manuscript. }\end{array}$ \\
\hline Prof. Ahmad Husain & $\begin{array}{l}\text { Supervised development } \\
\text { of work and acquisition of } \\
\text { data. }\end{array}$ \\
\hline
\end{tabular}

\section{References}

1. Curtis LJ, Bernier P, Jeejeebhoy K, Allard J, Duerksen D, et al. (2017) Costs of hospital malnutrition. Clin Nutr 36: 1391-1396.

2. van Bokhorst-de van der Schueren MA, LontermanMonasch S, de Vries OJ, Danner SA, Kramer MH, et al. (2013) Prevalence and determinants for malnutrition in geriatric outpatients. Clin Nutr 32: 1007-1011.

3. Leon-Sanz M, Brosa M, Planas M, García-de-Lorenzo A, Celaya-Pérez S, et al. (2015) PREDyCES study: The cost of hospital malnutrition in Spain. Nutrition 31: 1096-1102.

4. Fontes D, Generoso Sde V, Toulson Davisson Correia MI (2014) Subjective global assessment: A reliable nutritiona assessment tool to predict outcome in critically ill patients. Clin Nutr 33: 291-295.

5. Veramendi-Espinoza LE, Zafra-Tanaka JH, SalazarSaavedra O, Basilio-Flores JE, Millones-Sánchez E, et al. (2013) Prevalence and associated factors of hospital malnutrition in a general hospital; Peru, 2012. Nutr Hosp 28: $1236-1243$.

6. Rahman A, Wu T, Bricknell R, Muqtadir Z, Armstrong D (2015) Malnutrition matters in Canadian hospitalized patients: malnutrition risk in hospitalized patients in a tertiary care center using the malnutrition universal screening tool. Nutr Clin Pract 30: 709-713.

7. Dennis DM, Haak J, Carter V, Trevenen M, Cooper I (2018) Characteristics of hospitalized patients at the lowest and highest ends of the body mass index spectrum. J Nutri Med Diet Care 4: 024.

8. Mahakalkar CC, Suchita Modi, Meenakshi Yeola, Meghali N Kaple, Maneesha A Patwardhan, et al. (2014) Malnutrition in hospitalised patients; A real concern in surgical outcomes. Int J Res Med Sci 2: 250-257.

9. Alzahrani SH, Alamri SH (2017) Prevalence of malnutrition and associated factors among hospitalized elderly patients in King Abdulaziz University Hospital, Jeddah, Saudi Arabia. BMC Geriatr 17: 136.

10. Tannen A, Lohrmann C (2013) Malnutrition in Austrian hospital patients. Prevalence, risk factors, nursing interventions, and quality indicators: A descriptive multicentre study. J Adv Nurs 69: 1840-1849.

11. Pathirana AK, Lokunarangoda N, Ranathunga I, Santharaj WS, Ekanayake R, et al. (2014) Prevalence of hospital malnutrition among cardiac patients: Results from six nutrition screening tools. Springerplus 3: 412.

12. Susetyowati, Hadi H, Hakimi M, Asdie AH (2014) Development, validation and reliability of the simple nutrition screening tool (SNST) for adult hospital patient in Indonesia. Pakistan J Nutr 13: 157-163.

13. Aaldriks AA, Van der Geest LG, Giltay EJ, le Cessie S, Portielje JE, et al. (2013) Frailty and malnutrition predictive of mortality risk in older patients with advanced colorectal cancer receiving chemotherapy. J Geriatr Oncol 4: 218226.

14. Planas M, Álvarez-Hernández J, León-Sanz M, CelayaPérez S, Araujo K, et al. (2016) Prevalence of hospital malnutrition in cancer patients: A sub-analysis of the PREDyCES ${ }^{\circledR}$ study. Support Care Cancer 24: 429-435.

15. Lim SL, Ong KC, Chan YH, Loke WC, Ferguson M, et al. (2012) Malnutrition and its impact on cost of hospitalization, length of stay, readmission and 3-year mortality. Clin Nutr 31: $345-350$.

16. Thomas MN, Kufeldt J, Kisser U, Hornung HM, Hoffmann $J$, et al. (2016) Effects of malnutrition on complication rates, length of hospital stay, and revenue in elective surgical patients in the G-DRG-system. Nutrition 32: 249-254.

17. Gordon LJ, Tommy Cederholm, M Isabel TD Correia, M Christina Gonzalez, Ryoji Fukushima, et al. (2018) GLIM criteria for the diagnosis of malnutrition: A consensus report from the global clinical nutrition communnity. JPEN 0: 1-9.

18. Cederholm T, Jensen GL, Correia MITD, Gonzalez MC, Fukushima R, et al. (2018) GLIM criteria for the diagnosis of malnutrition-a consensus report from the global clinical nutrition community. Clin Nutr 1-9.

19. Wang F, Chen W, Bruening KS, Raj S, Larsen DA (2016) Nutrition screening tools and the prediction of clinical outcomes among Chinese hoszpitalized gastrointestinal disease patients. PloS One 11: e0159436.

20. Thompson KL, Davidson P, Swan WI, Hand RK, Rising C, 
et al. (2015) Nutrition care process chains: The "missing link" between research and evidence-based practice. J Acad Nutr Diet 115: 1491-1498.

21. Patel V, Romano $M$, Corkins MR, DiMaria-Ghalili RA, Earthman C, et al. (2014) Nutrition screening and assessment in hospitalized patients: A survey of current practice in the United States. Nutr Clin Pract 29: 483-490.

22. Corkins MR, Guenter $P$, DiMaria-Ghalili RA, Jensen GL, Malone A, et al. (2014) Malnutrition diagnoses in hospitalized patients: United States, 2010. JPEN J Parenter Enteral Nutr 38: 186-195.

23. Jensen GL, Compher C, Sullivan DH, Mullin GE (2013) Recognozing malnutrition in adults: Definitions and characteristics, screening, assessment, and team approach. JPEN J Parenter Enteral Nutr 37: 802-807.

24. Young AM, Kidston S, Banks MD, Mudge AM, Isenrig EA (2013) Malnutrition screening tools: Comparison aginst two validated nutrition assessment methods in older medical inpatients. Nutrition 29: 101-106.

25. White JV, Guenter P, Jensen G, Malone A, Schofield M (2012) Consensus statement: Academy of nutrition and dietetics and American society for parenteral and enteral nutrition: Characteristics recommended for the identification and documentation of adult malnutrition (undernutrition). JPEN J Parenter Enteral Nutr 36: 275-283.

26. Rasmussen $\mathrm{NH}$, Thomsen RW, Rasmussen $\mathrm{HH}$, Sogaard $M(2016)$ Validity of diagnostic coding for undernutrition in hospitals. Clin Nutr 35: 491-495.

27. Frank M, Sivagnanaratnam A, Bernstein J (2015) Nutrition assessment in elderly care: A MUST! BMJ Quality Improv Rep.

28. Leistra E, Langius JA, Evers AM, Van Bokhorst-de van der Schueren MA, Visser M, et al. (2013) Validity of nutritional screening with MUST and SNAQ in hospital outpatients. Eur J Clin Nutr 67: 738-742.

29. Skipper A, Ferguson M, Thompson K, Castellanos VH, Porcari J (2012) Nutrition screening tools: An analysis of the evidence. JPEN J Parenter Enteral Nutr 36: 292-298.

30. van Bokhorst-de van der Schueren MA, Guaitoli PR, Jansma EP, de Vet HC (2014) Nutrition screening tools: Does one size fit all? A systematic review of screening tools for the hospital setting. Clin Nutr 33: 39-58.

31. Hamada Y (2015) Objective data assessment (ODA) methods as nutritional assessment tools. J Med Invest 62: 119-122.
32. Budzynski J, Tojek K, Czerniak B, Banaszkiewicz Z (2016) Scores of nutritional risk and parameters of nutritional status assessment as predictors of in-hospital mortality and readmissions in the general hospital population. Clin Nutr 35: 1464-1471.

33. Hosmer DW, Lemeshow S (2000) Applied Logistic Regression. ( $2^{\text {nd }}$ edn), John Wiley \& Sons, Inc., USA.

34. Sanz EA, Garrido Siles M, Rey Fernández L, Villatoro Roldán R, Rueda Domínguez A, et al. (2009) Nutritional risk and malnutrition rates at diagnosis of cancer in patients treated in outpatient settings: Early intervention protocol. Nutrition 57: 148-153.

35. Wladisiuk M, Mlak R, Mazurkiewicz M, Malecca-Massalska $\mathrm{T}$ (2015) Malnutrition issues in patients with head and neck cancer. SM J Nutr Metabolism 1: 1002.

36. Mayasari M, Susetyowati, Lestariana W (2014) Simple nutrition screening tool (SNST) has good validity to identify risk of malnutrition on hospitalized elderly patients. PJN 13: 573-578.

37. Susetyowati, Djarwoto B, Faza F (2017) Nutrition screening tools as predictor of malnutrition for hemodialysis patients in Dr. Sardjito Hospital in Yogyakarta, Indonesia. Saudi J Kidney Dis Transpl 28: 1307-1313.

38. Correia MI, Hegazi RA, Higashiguchi T, Michel JP, Reddy BR, et al. (2014) Evidence-Based Recommendations for Addressing Malnutrition in Health Care: An Updated Strategy From the feed M. E. Global Study Group. J Am Med Dir Assoc 15: 544-550.

39. Todorovic V, Russell C, Stratton R, Ward J, Elia M (2003) The "MUST" Explanatory Booklet: A Guide to the Malnutrition Universal Screening Tool ('MUST') for Adults. (The Malnutrition Advisory Group, BAPEN).

40. Lomivorotov VV, Efremov SM, Boboshko VA, Nikolaev DA, Vedernikov PE, et al. (2013) Evaluation of nutritional screening tools for patients scheduled for cardiac surgery. Nutrition 29: 436-442.

41. Rohimah BB, Sugiarto $S$, Probandari AA, Wiboworini BB (2016) Comparison of a simple nutrition screening tool (SNST) compared with subjective global assessment (SGA) in body mass index (BMI) in T2 diabetes. Pak J Nutr 15: 412-418. 